http://jmscr.igmpublication.org/home/

ISSN (e)-2347-176x ISSN (p) 2455-0450

crossref DOI: https://dx.doi.org/10.18535/jmscr/v7i11.81

\title{
Clinical Profile and Systemic Associations in Patients of Vernal Keratoconjunctivitis
}

\author{
Authors \\ Dr Arti Sareen ${ }^{1 *}$, Dr Mudita Gupta ${ }^{2}$, Dr Mukta Sharma ${ }^{3}$, Dr Kusum Bhanoo ${ }^{4}$ \\ ${ }^{1}$ Medical Officer, DDUZH, Shimla \\ ${ }^{2}$ Assistant Professor, Department of Dermatology, IGMC, Shimla \\ ${ }^{3}$ Medical Officer, DDUZH, Shimla \\ ${ }^{4}$ Bhanoo Hospital, Near College Gate, Dhalpur, Kullu \\ *Corresponding Author
}

Dr Arti Sareen

\begin{abstract}
Background: Vernal Keratoconjunctivitis (VKC) is a chronic, recurrent, mostly bilateral, seasonal, allergic inflammation of the ocular surface, involving tarsal and/or bulbar conjunctiva occurring in children and young adults who may have associated eczema, rhinitis, asthma or family history of allergy.

Purpose: To study the clinical profile and systemic associations in patients of VKC presenting in a District Hospital set up of Northern India.

Material and Methods: All consecutive patients diagnosed as VKC presenting to eye OPD from 1 June 2018 to 31 May 2019 who consented to be a part of the study were included. Detail clinical history and ocular and systemic examination was done and recorded. The treatment prescribed and response was also observed.

Results: The total number of patients studied were 324. There were 217 males and 107 females. The main symptoms were itching seen in $85.21 \%$ patients, redness in $62 \%$ and watering in61.1\% patients. The major signs were papillary hypertrophy seen in $78.4 \%$ patients, limbal gelatinization in $63.3 \%$ patients and conjunctival congestion in $56.6 \%$ cases. Seasonal occurrence was found to be more common seen in $58.1 \%$ than perennial seen in 41.9\%patients. There were 11 patients who had associated rhinitis, 8 had associated eczema, 6 had asthma and 5 had a family history of allergy.

Conclusions: VKC is a allergic disease of the eye, more common in adolescent boys. It may have varied presenting symptoms but papillary hypertrophy is the commonest clinical sign present.

Keywords: Vernal Keratoconjunctivitis, itching, papillae.
\end{abstract}

\section{Introduction}

Vernal keratoconjunctivitis (VKC), also known as spring catarrh is an ocular allergic disease more commonly seen in paediatric age group .It is more common in boys especially in warm and dry climate in sub- tropics and tropics. As the name suggests it has a seasonal variation with onset in spring and summer. The clinical picture of VKC may vary from milder symptoms like ocular pruritus and tearing to troublesome manifestations like burning, foreign body sensation and photophobia. ${ }^{1}$ Chronic inflammation may lead to 
permanent visual impairment. ${ }^{2}$ Various clinical signs of VKC are lid edema, chemosis, tarsal papillae, Horner Trantas-Dots, brownish discoloration of eyeballs, darkened eyelids limbal infiltrates. In severe disease corneal involvement may occur with punctate keratitis, macro-erosions and ulceration. ${ }^{3}$

This study was conducted to study the demographic, clinical profile and systemic associations in patients of $\mathrm{VKC}$ presenting in a District Hospital set up of Northern India

\section{Material and Methods}

All consecutive cases attending eye OPD at our institute diagnosed as VKC who consented to be a part of the study were included in the study. All cases of allergic conjunctivitis or co-morbid conditions of eye were excluded. Prospective study was conducted in a district hospital of a hilly state between $1^{\text {st }}$ June 2018 to $31^{\text {st }}$ May 2019

The detailed history and ocular and systemic examination of the patients was recorded on a proforma which included their personal details, visual status, presenting complaints, signs, period of occurrence, history of systemic associations (which included history of rhinitis, atopy, asthma or family history of any allergies). Their ocular examination included their visual acuity by
Snellen Chart, visual axis, pupillary reactions, slit lamp examination and biomicroscopy. Keratometry was done in selected cases and intraocular pressure was recorded when needed.

The treatment was noted and response to treatment assessed at 2 weeks and 1 month post therapy. The patients were advised cold compresses and to wear dark glasses whenever they go outside. Treatment given was in the form of topical corticosteroids and topical mast cell stabilizer with antihistaminic activity. The patients were followed up after two weeks after which the topical steroids were tapered if a favorable response was seen and the mast cell stabiliser with antihistaminic activity was continued for a long term.

The data was entered in excel spread sheet and analyzed using epi info 7.2.2. All discrete variables were expressed as frequency and continuous variables as means.

\section{Results}

A total number of 324 patients of VKC were included in the study. The youngest patient was 9 months and the oldest 28 years The mean age of the patients was $6.04 \pm 4.56$ years. Maximum patients $44.4 \%$ patients were in age group of 11 15 years. There were only $6.5 \%$ patients $>20$ years The age distribution was summarised in Figure 1

Figure 1 Showing age distribution of patients of VKC

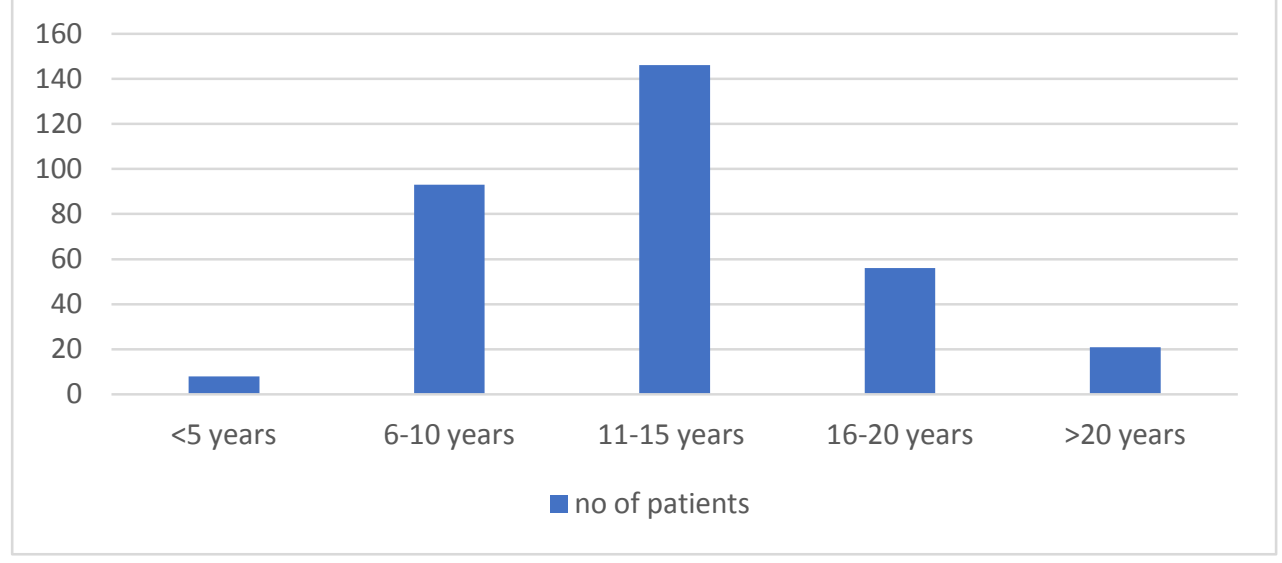

Males outnumbered females in a 2.02:1 as shown in Figure 2 There were 217 males (66.9\%)as shown in Table 2 which showed a clear male preponderance. 
Figure 2 Showing sex distribution of VKC patients

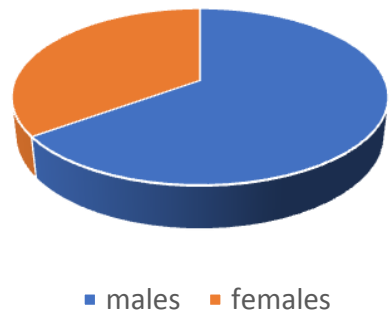

The maximum number of patients were seen in the month of May (30.2\%) followed by June (24.3\%). Majority of the patients had a seasonal occurrence of the disease seen in 188(58.1\%) while perennial disease was seen in $41.9 \%$ cases as shown in Figure 3
Figure 3 Showing different pattern of occurrence of $\mathrm{VKC}$

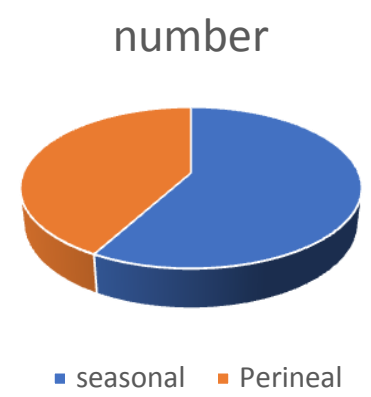

Figure 4 showing the distribution of various symptoms in VKC patients

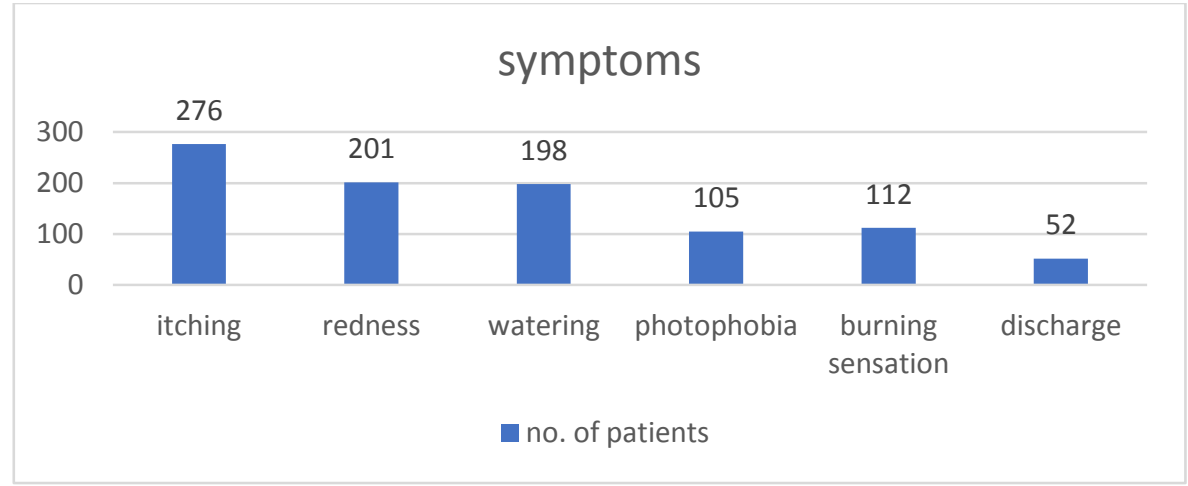

The commonest ocular sign was papillary hypertrophy in $78.4 \%$ patients followed by conjunctival congestion in $55.6 \%$ cases. The results were as shown in Table1

Table 1 showing the distribution of ocular signs in patients of VKC

\begin{tabular}{|l|l|c|c|}
\hline $\begin{array}{l}\text { Sr } \\
\text { No }\end{array}$ & Sign & $\begin{array}{c}\text { Number of } \\
\text { patients }\end{array}$ & $\begin{array}{c}\% \text { Age Of } \\
\text { patients }\end{array}$ \\
\hline 1 & Papillary Hypertrophy & 254 & $78.4 \%$ \\
\hline 2 & Conjunctival Congestion & 180 & $55.6 \%$ \\
\hline 3 & Perilimbal Gealtinisation & 205 & $63.3 \%$ \\
\hline 4 & SPK & 98 & $30.2 \%$ \\
\hline
\end{tabular}

The Visual Acuity at presentation was as shown in Table 2. There were $2.2 \%$ cases who showed severe visual impairment.
Table 2 Showing decreased visual acuity during episode of VKC

\begin{tabular}{|l|c|c|c|}
\hline S. NO & Visual Acuity & No Of Pts & \%Age Of Pts \\
\hline 1 & $6 / 6-6 / 18$ & 284 & $87.7 \%$ \\
\hline 2 & $6 / 18-3 / 60$ & 33 & $10.2 \%$ \\
\hline 3 & $<3 / 60$ & 7 & $2.2 \%$ \\
\hline
\end{tabular}

The predominant form of the disease was mixed seen in $258(79.6 \%)$ patients followed by palpebral in $46(14.2 \%)$. was seen in only $6.2 \%$ cases.

Systemic associations were seen were as shown in Table 3 which showed rhinitis to be the commonest association followed by asthma in 6 patients. 
Table 3 Showing association of systemic allergies

\begin{tabular}{|l|c|c|c|}
\hline Serial No & Association & $\begin{array}{c}\text { No. of } \\
\text { patients }\end{array}$ & $\begin{array}{c}\% \text { Age of } \\
\text { patients }\end{array}$ \\
\hline 1 & Rhinitis & 11 & $3.4 \%$ \\
\hline 2 & Eczema & 8 & $2.5 \%$ \\
\hline 3 & Asthma & 6 & $1.9 \%$ \\
\hline 4 & $\begin{array}{c}\text { Family History of } \\
\text { Allergy }\end{array}$ & 5 & $1.5 \%$ \\
\hline
\end{tabular}

Most of the patients responded to conservative management, topical mast cell stabilizers, topical corticosteroids and antihistaminics. Cyclosporine $2 \%$ eye drops were used in 11patients and suptrtarsal steroid injection was given to 4 patients. The patients had a slit lamp examination and applanation tonometry on each follow up to see for any treatment induced cataract and glaucoma to be detected at an early stage and the treatment substituted if it developed.

\section{Discussion}

VKC was first described by Arlt in 1846, Desmarres described the limbal findings later and Graefe the pavement like conjunctival granulations. ${ }^{4}$ VKC is a recurrent, bilateral allergic ocular inflammation more common in children with a aggravation during springs.

In our study mean age was 6.04 4.56 years, while Alemayehu et al observed a mean age of $9.74 \pm 4.0$ years and Rajappa et al of 13.75 years. ${ }^{5,6}$ Younger mean age in our patients was due to less number of adults seen in our study because of relative cooler climatic conditions.

Disease was found to be more common amongst boys with a male: female ratio of 2.02:1. In almost all studies conducted the disease has been found to be more common amongst boys with the male: female ratio being 4.1 to 2.1 and our study agrees well with these studies. ${ }^{5-8}$

$\mathrm{VKC}$ is a chronic recurrent seasonal as well as perennial allergic conjunctivitis. In our study seasonal occurrence was seen in $58.1 \%$ cases while Rajappa et al had seasonal VKC in $75.5 \%$ cases. $^{6}$

Maximum number of patients presented to our OPD in the hot dry summer months of May (30.2\%), followed by June (24.3\%), though patients presented to the eye OPD throughout the year. Even the patients who had a perennial form of the disease had an activation during the hot dry summer months. This was as seen in other studies by Saboo et al, Nagpal et al and Kansakar et al. ${ }^{8-10}$ Rajappa et al incontrast observed maximum cases in January. 6

Majority of the patients presented with itching followed by redness and watering. Intense itching with papillary hypertrophy have always been the impresa of VKC and we have seen in other studies too. ${ }^{5-9}$ Alemayehu et al observed itching in all of the VKC patients. ${ }^{5}$ Papillary hyperplasia was the commonest sign followed by conjunctival congestion and perilimbal gelatinization in our study. Sethi et al observed $78.70 \%$ to have palpebral papillae, limbal thickening was seen in $63.22 \%$ and $8.3 \%$ had perilimbal conjunctival pigmentation. $^{7}$

Clinically we found mixed form of VKC to be the commonest as seen in $79.6 \%$ followed by palpebral seen in $14.2 \%$ and then bulbar seen in in $6.2 \%$ of the cases. This was as seen in studies conducted in other parts of a country as seen by Saboo et al and Nagpal et al though Lambiese et al observed limbal subtype in $58.3 \%$ cases. $^{8,9,11}$ VKC thus may have varied ocular presentation from a trivial itching complaint to a potentially blinding disease. 12

It was seen that many patients had VKC had varied systemic allergies associated in corroboration which topic nature of the disease. In our study $2.5 \%$ had associated eczema, 3.4\% had rhinitis, $1.9 \%$ has asthma and $1.5 \%$ had a family history of atopy. In the study conducted by Saboo et al association of allergy in $4.9 \%$ of patients, Nagpal et al found it in 30\%, and Ukponmwan et al found it in $4.5 \%$ cases only. ${ }^{8,9,13}$ This association in our study corroborates with the findings of Tuft et al who showed that perennial VKC in tropical countries has lesser association with atopy. ${ }^{14}$

VKC is a self resolving condition, Bonini et al reported spontaneous recovery in $29.8 \%$ patients. ${ }^{15}$ Avoiding triggers is required to control 
the disease Medical therapy is the mainstay of treatment. Rarely is surgical intervention required. In conclusion we see that $\mathrm{VKC}$ is a recurrent allergic disorder seen in childhood especially in the hot and dry climate. Itching is the commonest presenting symptom and papillary hypertrophy the commonest ocular sign. Patient should be counselled about the recurrent nature of disease and treatment should be tailored according to severity of disease

\section{References}

1. Choleva P, Tole D, Churchill A. Allergic eye disease in children: identifying the signs and symptoms. International Journal of Ophthalmic Practice2014; 5: 50-2.

2. Bielory L. Allergic and immunologic disorders of the eye. Part II: ocular allergy. J Allergy Clin Immunol. 2000; 106:1019-32.

3. Kawuma M. The clinical picture of vernal kerato-conjunctivitis in Uganda.

Community eye health 2001; 14: 66 .

4. Sihota R, Tandon R. Diseases of the eye. Chap 4. In: Parson's diseases of the eye. 22nd edn. Elsevier India Private Limited 2015: p. 180

5. Alemayehu AM, Yibekal BT, Fekadu SA. Prevalence of vernal keratoconjunctivitis and its associated factors among children in Gambella town, southwest Ethiopia. PLOS 2018; Published: $\quad$ April 18, 2019 https://doi.org/10.1371/journal.pone.0215 528

6. Rajappa SA, Fatima F, Avinash S. A Clinical Study of Vernal Keratoconjunctivitis Int $\mathrm{J}$ Biomed Res 2014;5:284-7

7. Sethi M, Nanda R, Bali AS,Sadhotra P. Hospital based study of demography and clinical picture of vernal keratoconjunctivitis. Int $\mathbf{J}$ Res Med Sci 2018;6:65-8.
8. Saboo US, Jain M, Reddy JC, Sangwan VS. Demographic and clinical profile of vernal keratoconjunctivitis at a tertiary eye Care center in India. Indian $\mathbf{J}$ Ophthalmol 2013;61:486-9.

9. Nagpal H, Rani N, Kaur M. A retrospective study about clinical profile of vernal keratoconjunctivitis patients at a tertiary care hospital in Patiala, Punjab. Kerala J Ophthalmol 2017;61:189-91.

10. Kansakar I. Profile of vernal keratoconjunctivitis in Nepal: a hospital based study.Nepal Med Coll J. 2011;13:92-5.

11. Lambiase A, Minchiotti S, Leonardo A, Secchi AG, Rolando M, Calabria G, et al. Prospective, multicenter demographic and epidemiological study on vernal keratoconjunctivitis: A glimpse of ocular surface in Italian population. Ophthalmic Epidemiol 2009;16:38-41.

12. Tabbara KF. Ocular complications of vernal keratoconjunctivitis. Can J Ophthalmol 1999;34:88-92

13. Ukponmwan CV. Vernal conjunctivitis in Nigerian: 109 consecutive cases. Trip Doct 2003;33:242-5.

14. Tuft SJ, Cree IA, Wood M, Yorston D. Limbal vernal keratoconjunctivitis in the Tropics. Ophthalmology 1998;105:148993.

15. Bonini S, Bonini S, Lambiase A, Marchi S, Pasqualetti P, Zuccaro O, et al. Vernal keratoconjunctivitis revisited: a case series of 195 patients with long-term followup. Ophthalmology 2000: 107: 1157-63. 